\title{
Word frequency effects in associative and item recognition
}

\author{
STEVEN E. CLARK \\ University of California, Riverside, California
}

\begin{abstract}
The word frequency effect (WFE) has been taken as evidence that recall and recognition are in some way fundamentally different. Consequently, most models assume that recall and recognition operate via very different retrieval mechanisms. Experiment 1 showed that the WFE reverses for associative recognition, which requires discrimination between intact test pairs and recombinations of study list words from different study pairs. Experiment 2, in which word triples were used, revealed an interaction between word frequency and test type: for item recognition, performance was better for low-frequency words; however, for associative recognition and free recall, performance was better for high-frequency words. In Experiment 3, item recognition was tested: although overall performance was better for low-frequency words, the recognition advantage for items in intact pairs was larger for high-frequency words, suggesting two components in recognition memory. These results imply common mechanisms in recall and recognition. Theoretical implications are discussed within the framework of the SAM model.
\end{abstract}

Common high-frequency words are recalled better than rare low-frequency words. However, low-frequency words are recognized better than high-frequency words (see Gregg, 1976, for a review). This interaction, termed the word frequency effect (WFE), has been taken as evidence that recognition and recall are fundamentally different. It has been hypothesized that recall and recognition performance are based on the retrieval of different types of information and/or different retrieval processes (Anderson \& Bower, 1972; Gillund \& Shiffrin, 1984; Kintsch, 1970).

The present research focuses on word frequency effects in recognition, drawing a distinction between item recognition and associative recognition. A typical experimental procedure is the following. Subjects study a list of word pairs, denoted $A B, C D, E F$, etc. Item recognition requires subjects to make old-new judgments, distinguishing between $A$ (old) and $X$ (new) items. Associative recognition requires subjects to discriminate between intact $(A B)$ and rearranged $(A D)$ test pairs.

What is the relationship between item and associative recognition, and what might this relationship tell us about the more general question regarding the relationship between recognition and recall? Procedurally, item and associative recognition share two characteristics: (1) All relevant words are presented to subjects (unlike in recall

This research was supported by Grant 5-538430-1990-7 from the Academic Senate of the University of California, Riverside. I wish to thank Michael Fitzwater for assistance in data collection and analysis, and Robert Proctor, Robert Greene, and two anonymous reviewers for helpful comments on an earlier draft. Thanks to Bill Hockley and Rich Burchett for helpful discussions. Correspondence should be addressed to Steven E. Clark, Department of Psychology, University of California, Riverside, CA 92521 (e-mail: clark@ucrvms.bitnet). tasks, in which list words must be retrieved by the subject); and (2) both tasks require old-new judgments, differing only in how old and new are defined.

However, many researchers have suggested a similarity between recall and recognition of word groups (of which associative recognition is one case). For instance, subjects may discriminate between $A B$ and $A D$ by recalling for each case the word that was paired with $A$ (Anderson, 1974; Humphreys, 1978; Mandler, 1980; Wolford, 1971). This implies that associative recognition and recall share retrieval processes. The issue of retrieval processes aside, associative recognition and recall performance may be based on retrieval of the same kind of information (associative pathways or unitized associations), unlike item recognition, which is based on retrieval of item-specific information (Humphreys, 1976, 1978; Murdock, 1982). Thus, the process and information differences proposed for recall and recognition may hold for associative and item recognition as well.

The present research is conducted within the theoretical framework of the SAM model (Gillund \& Shiffrin, 1984; Raaijmakers \& Shiffrin, 1980), for three reasons: (1) SAM assumes that item and associative recognition are based on the same retrieval mechanisms and the same kinds of information; (2) Gillund and Shiffrin (1984) give a good account of a wide range of word frequency results; (3) SAM unambiguously predicts that word frequency will have the same effect for both item and associative recognition. The experiments reported here provide a strong test of the SAM model account of WFEs. To the extent that associative and item recognition differ, and to the extent that associative recognition shares properties with recall, a high-frequency-word advantage should be obtained for associative recognition, contrary to the predictions of the SAM model. 
In the next section, the SAM model will be described briefly, to illustrate the properties that produce word frequency predictions. Readers less concerned with the details of the model may skip this section, but should take with them the following bottom line: SAM's predictions for the WFE are parameter specific. Thus, by varying parameter values, a high- or low-frequency advantage can be predicted. However, the prediction will be the same for both item and associative recognition. Parameters that produce a low-frequency advantage for item recognition will also produce a low-frequency advantage for associative recognition. Similarly, if a high-frequency advantage is predicted for item recognition, it is also predicted for associative recognition. ${ }^{1}$

\section{THE SAM MODEL}

The SAM model will be described in sufficient detail to illustrate its predictions for WFEs in recall and recognition. Thus, many aspects of the model are simplified or omitted. Readers seeking additional quantitative details are referred to the Appendix or to the original papers of Raaijmakers and Shiffrin (1980) and Gillund and Shiffrin (1984).

Events (words) are represented in separate units called images. Recall and recognition performance are determined by the retrieval strengths between the cues used to probe memory and the images in memory (functionally the images in memory are restricted to the words on the list). The retrieval strength between a given cue $Q_{i}$ and image $I_{j}$ is denoted $S\left(Q_{i}, I_{j}\right)$.

\section{Recall}

Recalling a word is a two-step process. The image of the word must first be accessed or sampled, and then the information stored in that image must be recovered. The likelihood of sampling a particular image with a given set of cues is based on the relative strength of the cues to that image. Thus, $I_{j}$ will be sampled using cue $Q_{i}$ to the extent that $Q_{i}$ is uniquely connected to $I_{j}$ (and weakly connected to other images). Recovery of the information in the image, however, is based on the absolute magnitude of the cue-to-image strengths. Thus, once $I_{j}$ is sampled, other images in memory do not matter (for recovery of $\boldsymbol{I}_{j}$ information).

\section{Recognition}

It is assumed that memory is probed with the test item(s) and context as cues. The result of this probe is a scalar index of the familiarity of the test item(s). Test items with familiarity above some criterion are called old.

Familiarity is computed as the sum of the cue-to-image strengths between the cues (test items and context) and the images in memory. Thus, the familiarity of the test item is not due only to its match to its own image in memory, but also to its match to other images in memory. Recognition, therefore, is based on a global match of the test items to memory.

\section{Application to WFE}

Before I describe the model's applications to the WFE, I must describe its major parameters. These parameters, which give values for $S\left(Q_{i}, I_{j}\right)$, are determined as follows. The retrieval strength between a word cue and its corresponding image in memory is termed a self-strength, denoted $c$. The strength between a word cue and the image of a word with which it was rehearsed has an interitem strength, $b$. The strength between a word cue and the image of a word with which it was not rehearsed has a small residual value $d$. Finally, it is assumed that any probe of memory uses context as a cue; this context-toimage strength is denoted $a$.

To account for the WFE, Gillund and Shiffrin (1984) assumed that preexperimental associations (residual strengths) and episodic associations due to rehearsal (interitem strengths) are stronger for high-frequency words than for low-frequency words. In terms of parameters, $b_{\mathrm{H}}>b_{\mathrm{L}}$ and $d_{\mathrm{H}}>d_{\mathrm{L}}$, where the subscripts $\mathrm{H}$ and $\mathrm{L}$ indicate word frequency. Self- and context strengths are assumed to be equal for high- and low-frequency words. This set of assumptions produces a high-frequency-word advantage in recall for two reasons. (1) Increasing $b$ and $d$ relative to the self-strength $c$ reduces the likelihood that a word cue will sample its own image; this self-sampling is, of course, unproductive. (2) Increases in the absolute strengths (higher $b$ and $d$ ) increase the chances of recovering images that have been sampled.

The same assumptions also correctly produce a lowfrequency-word advantage for item recognition. It should be emphasized that familiarity is a sum of cue-to-image strengths, including not only self-strengths (the connection of the test item to itself), but also interitem and residual strengths (the connection of the test item to other items in memory, including words with which the test item was rehearsed). Thus, because $b_{\mathrm{H}}>b_{\mathrm{L}}$ and $d_{\mathrm{H}}>d_{\mathrm{L}}$, high-frequency targets will be more familiar than lowfrequency targets. However, this advantage is more than offset by increased familiarity of high-frequency distractors (due entirely to $d_{\mathrm{H}}>d_{\mathrm{L}}$ ). It is clear that the model's predictions for recognition are produced by a parameterspecific balance of $b$ and $d$ values.

Why are associative recognition predictions linked to item recognition? SAM assumes that associative recognition and item recognition are based on the same summedstrength familiarity. Thus, discrimination of $A$ from $X$ and $A B$ from $A D$ are both based on sums of self-strengths, interitem strengths, and residual strengths. The derivation of this prediction is given in the Appendix.

As a final note, the separation of retrieval strengths into self-strengths and interitem strengths parallels a distinction, made by Humphreys (1976), Hunt and Einstein (1981), Murdock $(1974,1982)$, and others, between itemspecific and associative information. In SAM, associative recognition is based not only on associative information, but also on item-specific information. Likewise, item recognition is based on associative connections as well as item-specific information. 


\section{EXPERIMENT 1}

The purpose of Experiment 1 was to compare the effect of word frequency in item and associative recognition. The SAM model assumes that these two kinds of recognition utilize the same kinds of retrieval processes to access the same kinds of information and thus should show the same effect of word frequency. Other models (Anderson, 1974; Humphreys, 1976; Mandler, 1980; Murdock, 1982) assume that associative recognition is based on information and/or retrieval processes that are different from item recognition and are more similar to recall. On the basis of these models, a high-frequencyword advantage should be demonstrated for associative recognition, contrary to the low-frequency-word advantage typically shown for item recognition.

Subjects studied lists of high- or low-frequency-word pairs and were tested with item recognition, associative recognition, or free recall, following different study lists.

\section{Method}

Subjects. Sixty-five undergraduates from the University of California at Riverside participated for credit in an introductory psychology course.

Materials and Procedure. All study and test words were sampled from the Thorndike and Lorge (1944) and Kucera and Francis (1967) word frequency norms. Words with frequencies of $50+/$ million (in both norms) were defined as high in frequency; words with frequencies less than $4 /$ million were defined as low frequency.

The subjects were presented with six lists of 21 word pairs. Three of the lists consisted of high-frequency words, and three consisted of low-frequency words. Pairs were presented at a 3-sec/pair rate. Subjects were instructed to learn the pairs by forming interactive visual images, or by creating sentences with the two words in each pair. This kind of interactive rehearsal instruction was given, because separate rehearsal of words leads to very low performance in associative discrimination tasks (Bain \& Humphreys, 1988; Greene, 1990).

Following each study list, subjects performed a $30-\mathrm{sec}$ mental addition task, in which they added 15 singly presented digits between 4 and 9 . Subjects were given one of three kinds of memory test following the mental addition task: item recognition, associative recognition, or free recall. Subjects did not know the test condition prior to study list presentation, but they were fully instructed about the nature of the three kinds of test, and they received practice before the data were collected.

Item recognition. On each test trial, either one study list word or a new word was presented for an old or new judgment. Twenty old and 20 new words were tested. Half of the targets and half of the distractors were presented as left-hand pair members. A blank line next to the test word indicated its position. Position within the pair was maintained for study list words. Also, only 1 word from a studied pair was tested.
Associative recognition. Each test trial presented either two words studied together (intact), or (wo words from the study list but from different pairs (rearranged). The subject was to respond "old" for intact pairs and "new" for rearranged pairs. Seven intact and seven rearranged pairs were tested. A given study pair was tested only once; thus, if $A D$ was tested, neither $B$ nor $C$ was tested. ${ }^{2}$ Word position was always maintained; $B A$ would not be presented as a test pair.

Free recall. The subjects were given $4 \mathrm{~min}$ to write down as many words from the study list as possible. They were instructed that they should write both words in a pair if they remembered them both, but they were also told that they were not required to write down both words in a pair.

Selection of words and assignment to conditions were both randomly determined for each subject, as were the order of recognition test trials and the order of study list presentation and test conditions. All stimuli were presented on Atari 1040ST computer terminals, and responses were collected on a standard computer keyboard.

\section{Results}

Average hit rates (HR) and false alarm rates (FAR), hit rate minus false alarm rate (HR-FAR), recognition $d^{\prime}$ averaged across subjects, and proportion of words recalled are shown in Table 1. The recognition results were evaluated statistically using HR -FAR and $d^{\prime}$ in separate analyses. All statistical tests were done for both measures. Both analyses showed the same pattern of results (and sphericity tests were nonsignificant for both analyses). Results are presented only for HR-FAR. ${ }^{3}$

This analysis revealed better performance for item recognition than for associative recognition $[F(1,64)=20.93$, $\left.M S_{\mathrm{e}}=.068, p<.001\right]$, no main effect of word frequency $\left[F(1,64)=0.96, M S_{\mathrm{e}}=.043\right]$, and a frequency $\times$ test type interaction $\left[F(1,64)=8.11, M S_{\mathrm{e}}=.046, p<\right.$ .006].

Separate tests of the WFE for item and associative recognition revealed the source of the interaction. Item recognition showed a small, statistically unreliable advantage for low-frequency words $\left[F(1,64)=3.41, M S_{\mathrm{e}}=.025\right.$, $p<.07]$, and associative recognition showed a reliable high-frequency-word advantage $\left[F(1,64)=5.14, M S_{\mathrm{e}}=\right.$ $.065, p<.03$ ].

The high-frequency associative recognition advantage is due primarily to a lower false alarm rate for highfrequency words, which was .073 lower $[t(64)=2.79$, $p<.011$. The hit rate was higher for high-frequency words, but the .031 difference was not statistically significant. For single-item recognition, the hit rate was higher and the false alarm rate was lower for low-frequency words, but neither difference was statistically reliable.

Table 1

Average Hit and Fabe Alarm Rates for Single-Item and Associative Recognition, and Proportion of Words Recalled, in Experiment 1

\begin{tabular}{|c|c|c|c|c|c|c|c|c|c|}
\hline \multirow{3}{*}{$\begin{array}{c}\text { Word } \\
\text { Frequency }\end{array}$} & \multicolumn{8}{|c|}{ Recognition } & \multirow{3}{*}{$\begin{array}{c}\% \\
\text { Recalled }\end{array}$} \\
\hline & \multicolumn{4}{|c|}{ Item } & \multicolumn{4}{|c|}{ Associative } & \\
\hline & HR & FAR & HR-FAR & $d^{\prime}$ & HR & FAR & HR-FAR & $d^{\prime}$ & \\
\hline $\begin{array}{l}\text { Low } \\
\text { High }\end{array}$ & $\begin{array}{l}.788 \\
.759\end{array}$ & $\begin{array}{l}.135 \\
.157\end{array}$ & $\begin{array}{l}.653 \\
.602\end{array}$ & $\begin{array}{l}2.11 \\
1.93\end{array}$ & $\begin{array}{l}.747 \\
.776\end{array}$ & $\begin{array}{l}.319 \\
.246\end{array}$ & $\begin{array}{l}.428 \\
.530\end{array}$ & $\begin{array}{l}1.37 \\
1.80\end{array}$ & $\begin{array}{l}.115 \\
.146\end{array}$ \\
\hline
\end{tabular}

Note-HR, hit rates; FAR, false alarm rates; HR-FAR, hit rates minus false alarm rates; $d^{\prime}$, recognition $d^{\prime}$ across all subjects. 
Recall. Recall results, analyzed as the proportion of words recalled without respect to pairs, showed an advantage for high-frequency $(.146)$ words over low-frequency (.115) words $\left[F(1,64)=6.54, M S_{\mathrm{e}}=.0048, p<.02\right]$.

\section{Discussion}

Experiment 1 showed that associative recognition was better for high-frequency words than for low-frequency words, while low-frequency words did just very slightly better than high-frequency words for item recognition (although this was not statistically significant). In addition, a high-frequency-word advantage was shown for free recall. Thus, with respect to word frequency, associative recognition follows the pattern of results for recall, rather than for item recognition. These results are contrary to the predictions of the SAM model, in which predictions for item and associative recognition are linked together.

The lack of a significant low-frequency-word advantage for item recognition presents a potential problem for interpretation, because it allows for the possibility that the high-frequency-word advantage in associative recognition occurs only under conditions that eliminate WFEs for item recognition. However, as Experiment 2 will show, this is not the case.

The attenuated WFE may have been produced by the requirement to connect the two words within the pair. Lockhart, Craik, and Jacoby (1976) suggested that the low-frequency-word advantage for item recognition may be due to inadequate processing of high-frequency words, since high-frequency words are more easily encoded. From this, Rao and Proctor (1984) reasoned that encoding tasks that necessitate more semantic or elaborative processing should discourage the "lazy" processing of highfrequency words and therefore reduce the magnitude of the low-frequency-word advantage. Several experiments have yielded results consistent with this reasoning (Balota \& Neely, 1980; Eysenck, 1979; Rao \& Proctor, 1984; see also Mutter \& Hashtroudi, 1987).

SAM can account for variations in the size of the lowfrequency-word advantage in item recognition by adjusting parameters. However, what SAM cannot do is predict that word frequency has different effects on item and associative recognition; it cannot predict a small lowfrequency-word advantage (or even a null result) for item recognition in conjunction with a large high-frequencyword advantage for associative recognition.

The interaction of word frequency with test condition suggests that item and associative recognition involve different kinds of information, different retrieval processes, or both. Although SAM does distinguish between item and associative information, both information types contribute to item and associative recognition, and consequently this version of SAM cannot predict the interaction of word frequency with recognition test type. Other modified versions of SAM that are more capable will be discussed later.

The interaction is inconsistent with models in which item and associative recognition utilize the same infor- mation and the same retrieval processes. Such models include SAM and the MINERVA 2 model of Hintzman (1984, 1988), and Pike's (1984) Matrix model.

The results do not distinguish between retrieval-based and information-based accounts. However, one interesting aspect of the results is that the high-frequency advantage in associative recognition was due primarily to lower false alarm rates for high-frequency words, rather than higher hit rates. Glanzer and Adams $(1985,1990)$ have noted that for item recognition, performance differences due to word type almost always show a mirror effect: better recognition is due both to higher hit rates and to lower false alarm rates. Typically, for item recognition, lowfrequency words show this pattern of higher hit rates and lower false alarm rates. However, such a mirror effect was not found in Experiment 1 for the high-frequency advantage for associative recognition.

A recall-based explanation of the high-frequency advantage provides a natural account of this aspect of the results. One way in which rearranged distractors may be rejected is to use one of the test words as a cue to recall its original pairmate. For example, $A D$ may be rejected if subjects recall that $A$ was paired with $B$ (and, therefore, not $D$ ). This factor should favor high-frequency words, since they are recalled better than low-frequency words. This kind of recall may operate for targets as well, but it may not produce as much of an advantage for highfrequency words. The reason is that for targets, both words are present in the test pair; the superiority of highfrequency words in recall may be reduced because the words to be recalled are available in the test pair.

An alternative to both recall-based and informationbased accounts of the high-frequency advantage is based on encoding match (Light \& Carter-Sobell, 1970). When a target word is tested in a verbal context that does not match its study context, it may be encoded differently. Thus, the familiarity of rearranged pairs would be decreased relative to intact pairs, allowing intact-rearranged discrimination and context effects. Such proposals have been incorporated into independent strength models (Kintsch, 1978), network models (Anderson \& Bower, 1972), and one global matching model (SAM; Clark \& Shiffrin, 1987).

It has been argued that since high-frequency words have more meanings than low-frequency words do (Jastrzembski, 1981), they should be more sensitive to changes in verbal context and thus show greater encoding match effects than low-frequency words do (Reder, Anderson, \& Bjork, 1974; Muter, 1984). This factor could produce the highfrequency advantage for associative recognition found in Experiment 1. The encoding match explanation is fundamentally different from recall-based or information-based accounts in that (1) it is based entirely on item-specific factors, and (2) it places the locus of context effects prior to probing memory (at encoding). Because the facilitative effects of reinstating context are presumed to occur prior to retrieval, and are assumed to be larger for highfrequency words, one would expect facilitation for high- 
frequency words for item recognition, if intact groups were tested. This prediction was tested in Experiment 2.

A second purpose of Experiment 2 was to investigate a specific hypothesis concerning the operation of recall in associative recognition. Atkinson and Juola (1974) proposed a conditional search model in which decisions are based on familiarity when familiarity values are extreme. However, for intermediate levels of familiarity, a search is initiated. Thus, a search is utilized in difficult cases in which the familiarities of targets and distractors are close. One reason why subjects might utilize a search for associative recognition is that the difference in familiarity for intact and rearranged tests may be small. In Experiment 2, subjects were tested with two different associative discriminations, which varied in difficulty. The difficulty hypothesis predicts a larger high-frequency advantage for the more difficult discrimination.

\section{EXPERIMENT 2}

In Experiment 2, words were studied in triples $(A B C$, $D E F, G H I$, etc.), with each study list followed by one of five kinds of test condition: single-item recognition, triple-item recognition, one of two kinds of associative recognition, or free recall. Single-item recognition requires discrimination of single list words from single nonlist items $(A$ vs. $X)$; triple-item recognition requires discrimination of old triples from new triples ( $A B C$ vs. $X Y Z$ ). The comparison of single- and triple-item recognition provides a test of the encoding match hypothesis. If the match of verbal context produced the high-frequency advantage for associative recognition in Experiment 1, then matching context should have a similar effect in triple-item recognition, producing a high-frequency advantage.

Two kinds of associative recognition were tested. In one condition, intact triples were tested against rearrangements consisting of two words from one study triple and a third word from another triple. These rearrangements are denoted as $A B F$. In the other condition, rearranged tests contained words from three different study triples; they are denoted $A E I$. The first task is termed Assoc-2 (since the test items are from two different study triples), and the second is termed Assoc-3.

Assoc-2 recognition should be more difficult than Assoc-3, since Assoc-2 rearrangements are more similar to intact triples than are Assoc-3 rearrangements. Atkinson and Juola (1974) proposed that search is utilized when familiarities of targets and distractors are too close to make accurate recognition judgments. Thus, for difficult Assoc-2 discriminations ( $A B C$ vs. $A B F$ ), recall should be utilized more often than for easier Assoc-3 discriminations ( $A B C$ vs. $A E I$ ), producing a larger high-frequency advantage for Assoc-2.

\section{Method}

Subjects. The subjects were 52 different students from the same pool that was used in Experiment 1.
Materials and Procedure. Words for study and test were selected with the same criteria from the same sources as before. Ten study lists, each consisting of 24 words triples $(A B C, D E F, G H I$, etc.), were presented at a rate of $3 \mathrm{sec} /$ triple. Five lists consisted of high-frequency and five of low-frequency words. Each study list was followed by one of five kinds of memory test: single item, triple item, Assoc-2, Assoc-3, or free recall. Word frequency and test type were combined factorially to give 10 study-test conditions. The details of the test conditions are given below.

Single-item recognition. On each test trial, a single old $(A)$ or a single new word $(X)$ was presented. For target and distractor trials, the test word was selected from each of the three possible positions in the triple with equal probability. Six old and six new items were tested.

Triple recognition. Six intact $(A B C)$ and six new $(X Y Z)$ triples were tested.

Assoc-2. Six intact and six rearranged triples were tested. The rearranged tests, denoted $A B F$, consisted of two words from the same study triple, with the third word picked randomly from a different triple. In rearranged triples, the nonmatching word appeared in each position equally often.

Assoc-3. Six intact and six rearranged triples were tested. The rearranged tests consisted of three items from three different study triples $(A E I)$.

For all recognition test sequences, a given study triple was tested only once. For single-item recognition, for example, if $A$ was tested on one trial, $B$ and $C$ would not be tested. For associative tests, words from the same study triple were not tested in different rearranged triples (i.e., $A E I$ and $G B F$ could not both be tested). Order of words within pairs was maintained.

The number of test trials was the same for all recognition tests. Thus, differences between test conditions could not be attributed to changes in performance over varying numbers of test trials (see Schulman, 1974). The study list items tested were selected randomly.

Free recall. The subjects were allowed 4 min to recall as many words from the immediately preceding list as possible in any order. The subjects were instructed that it was not nocessary to recall items as triples, but that if they did remember groupings, they should identify them as such.

As in Experiment 1, the subjects were fully instructed regarding the nature of the memory tasks; however, for any given study list, the type of test was not revealed until after study list presentation. The subjects were instructed to form connections between study words within a triple, by using the words in a sentence or by forming a visual image.

Order of study and test conditions were randomly determined for each subject, as were selection of words, assignment of words to conditions, and order of presentation for study triples and recognition test trials. The apparatus was the same as in Experiment 1.

\section{Results}

Hit rate, false alarm rate, and $d^{\prime \prime}$ were calculated for each subject for each test condition and are shown in Table 2 . Two $2 \times 4$ (word frequency $\times$ recognition test type) analyses were computed, one on hit rate minus false alarm rate, the other with $d^{\prime}$. For the $d^{\prime}$ analysis, scores of 1 and 0 were estimated according to the procedure described by Murdock and Ogilvie (1968). Both analyses gave virtually identical results (and both showed nonsignificant tests of sphericity), and only the hit rate minus false alarm rate analyses are reported. Recall results were analyzed separately.

The analysis showed a main effect of recognition test type $\left[F(3,147)=52.31, M S_{\mathrm{e}}=.065, p<.001\right]$, no 
Table 2

Hit and False Alarm Rates and $d^{\prime}$ for Experiment 2

\begin{tabular}{|c|c|c|c|c|c|c|c|c|c|c|c|c|}
\hline & \multicolumn{3}{|c|}{ Single } & \multicolumn{3}{|c|}{ Triple } & \multicolumn{3}{|c|}{ Assoc-3 } & \multicolumn{3}{|c|}{ Assoc- 2} \\
\hline & HR & FAR & $d^{\prime}$ & HR & FAR & $d^{\prime}$ & HR & FAR & $d^{\prime}$ & HR & FAR & $d^{\prime}$ \\
\hline $\begin{array}{l}\text { Low frequency } \\
\text { High frequency }\end{array}$ & $\begin{array}{l}.66 \\
.64\end{array}$ & $\begin{array}{l}.15 \\
.24\end{array}$ & $\begin{array}{l}1.65 \\
1.26\end{array}$ & $\begin{array}{l}.81 \\
.69\end{array}$ & $\begin{array}{l}.09 \\
.07\end{array}$ & $\begin{array}{l}2.40 \\
2.07\end{array}$ & $\begin{array}{l}.67 \\
.62\end{array}$ & $\begin{array}{l}.38 \\
.26\end{array}$ & $\begin{array}{r}.88 \\
1.11\end{array}$ & $\begin{array}{l}.66 \\
.61\end{array}$ & $\begin{array}{l}.45 \\
.30\end{array}$ & $\begin{array}{l}.62 \\
.97\end{array}$ \\
\hline $\begin{array}{l}t \\
p\end{array}$ & $\begin{array}{l}.69 \\
\text { n.s. }\end{array}$ & $\begin{array}{r}2.44 \\
.02\end{array}$ & & $\begin{array}{r}3.06 \\
.01\end{array}$ & $\begin{array}{l}.65 \\
\text { n.s. }\end{array}$ & & $\begin{array}{r}1.04 \\
\text { n.s. }\end{array}$ & $\begin{array}{r}3.31 \\
.01\end{array}$ & & $\begin{array}{r}1.40 \\
.10\end{array}$ & $\begin{array}{l}4.88 \\
.001\end{array}$ & \\
\hline
\end{tabular}

Note-HR, hit rates; FAR, false alarm rates; Assoc-3, discrimination of intact $A B C$ from rearranged $A E I$ probe in which test words are from three different study triples; Assoc-2, discrimination of intact from $A B F$ probe in which test words are from two different study list triples. Also included are $t$ values comparing HRs and FARs for high- and low-frequency words, plus corresponding $p$ values.

main effect for word frequency $\left[F(1,147)=0.15, M S_{\mathrm{e}}=\right.$ $.068]$, but a significant interaction $[F(3,147)=5.64$, $\left.M S_{\mathrm{e}}=.062, p<.002\right]$.

Separate analyses were performed to evaluate the word frequency effect for each of the recognition test conditions. These analyses showed a low-frequency advantage for both single-item recognition $\left[F(1,49)=5.30, M S_{\mathrm{e}}=\right.$ $.064, p<.05]$ and triple-item recognition $[F(1,49)=$ $\left.6.77, M S_{e}=.047, p<02\right]$. However, a quite different pattern was shown for both associative discriminations: a small, statistically unreliable high-frequency-word advantage was shown for Assoc-3 recognition $[F(1,49)=$ $\left.1.88, M S_{\mathrm{e}}=.084, p>.15\right]$, and a large high-frequency advantage for Assoc-2 recognition $[F(1,49)=4.78$, $\left.M S_{\mathrm{e}}=.063, p<.05\right]$.

Analyses of hit and false alarm rates were performed to determine the source of the WFEs. The results are straightforward for the two associative recognition tasks. For both Assoc-2 and Assoc-3, hit rates were slightly lower for high-frequency words than for low-frequency words, although the differences were not statistically significant. For both test conditions, false alarm rates were much lower for high-frequency words, .12 lower for Assoc-3, and .15 lower for Assoc-2. Thus, it is clear that the high-frequency advantage in associative recognition was due entirely to rejection of rearranged distractors.

For single-item recognition, hit rates did not differ for high- and low-frequency words, but the false alarm rate was .09 smaller for low-frequency words. A very different pattern emerged for triple-item recognition: false alarm rates did not differ, but hit rates were larger for lowfrequency words. Thus, while a low-frequency advantage was obtained for both single- and triple-item recognition, it was produced in different ways.

Two additional tests were conducted to compare the magnitude of the low-frequency advantage for single- and triple-item recognition, and the magnitude of the highfrequency advantage for Assoc-3 and Assoc-2 recognition. Neither of these tests showed a reliable difference (both $F$ s $<1$ ).

Overall, recall performance was poor. The average proportion of words recalled was 0.069 for high-frequency words, and 0.047 for low-frequency words, corresponding to 4.96 and 3.4 items, respectively (out of 72 ). The performance difference was reliable $[F(1,49)=11.25$, $\left.M S_{\mathrm{e}}=.001, p<.005\right]$.

\section{Discussion}

Experiment 2 showed both a high-frequency advantage for associative recognition (although it was small for Assoc-3) and a low-frequency advantage for item recognition. The high-frequency associative recognition advantage replicates Experiment 1, showing that the effect is reliable. Moreover, the high-frequency associative advantage occurred concurrently with a significant low-frequency advantage for item recognition.

The high-frequency advantage was due entirely to better rejection of rearranged distractors. This was also consistent with Experiment 1, which resulted in only a small hit rate advantage for high-frequency words. Again, a natural interpretation of this result is that high-frequency words in rearranged pairs provide better access to original pair members, leading to correct rejections.

On the basis of the Atkinson and Juola (1974) model, it was predicted that recall processes would play a larger role for the more difficult associative discrimination. However, the results provide only weak support for this proposal in the current setting. Although Assoc-2 recognition was clearly more difficult than Assoc-3 recognition, the high-frequency advantage was not significantly larger for Assoc-2 recognition (although it was in the predicted direction).

Experiment 2 showed that the high-frequency-word advantage in associative recognition occurs under encoding conditions that produce a low-frequency-word advantage in item recognition. Experiment 1 resulted in a very small low-frequency-word advantage for recognition of single items studied in pairs. A possible explanation for this result was based on Lockhart et al.'s (1976) suggestion that the low-frequency advantage is due to inadequate processing of high-frequency words. In Experiment 1, it may have been that the requirement to form a connection between the words in the pair forced a more equitable processing of the words, thus reducing the low-frequencyword advantage.

But why didn't the same factor produce a small lowfrequency advantage in Experiment 2? A tentative expla nation is that in larger groups of words, associations may 
be formed without giving equal processing to all of the words. For instance, the subject may work to form an association between $A$ and $B$, and having done so, simply "stick $C$ on the end." This may be more likely to occur for high-frequency words that are relatively easier to "stick together" than for low-frequency words that may require more item-specific processing for connections between the words to be found. This is, of course, all quite speculative, but it raises for future research the question of how much item-specific processing is involved in forming episodic associations.

The size of the low-frequency advantage was the same for single-item and triple-item recognition. Thus, differences between item and associative recognition are not due to the mere presence of additional word cues at test. This argues against an encoding match interpretation of the high-frequency advantage for associative recognition. Although the magnitude of the low-frequency advantage was the same for single- and triple-item recognition, the advantage was achieved in different ways; it was due primarily to lower false alarm rates for single items, and due entirely to higher hit rates for word triples.

It is likely that subjects used complex decision rules for triple-item recognition. Since the subjects knew that all of the words were old or all were new, some responses may have been based on a single word with very high or very low familiarity. Other factors may also have been operating for triple-item recognition. For example, it is likely that for old triples the separate familiarities of the test words would be correlated. Various other conditional response rules may have been adopted. An interesting question would be to ask why the low-frequency advantage was produced in different ways for triple- and singleitem recognition; this, however, is not central to the present work, so it will not be pursued further here.

In summary, Experiments 1 and 2 clearly show that WFEs are different for item and associative recognition. Item recognition shows a low-frequency-word advantage, and associative recognition shows a high-frequency-word advantage.

The account of the WFE given by Gillund and Shiffrin (1984) within the framework of the SAM model cannot predict different effects of word frequency on item and associative recognition. The reason is that the mechanism that would produce the high-frequency associative recognition advantage - increasing the interitem connection strength-increases item recognition as well as associative recognition. In the original version of SAM (in which the account of the WFE is framed), interitem associations contribute to the familiarity of the single words that are part of the association.

One of two modifications is necessary. One is to assume that the $A B$ (or $A B C$ ) association contributes only to the familiarity of $A B$ (or $A B C$ ), but not to the familiarity of the single words that are part of that association. This modification could be incorporated into the summedstrength global familiarity model, by assuming that associations are stored as higher order units. This assump- tion was adopted to account for recall results of Shiffrin, Murnane, Gronlund, and Roth (1988). For the current purposes, the higher order unit would separate the association from its component words. ${ }^{4}$

Alternatively, recall-like retrieval processes may be operating in associative recognition. WFEs in Experiments 1 and 2 showed a high-frequency-word advantage for free recall and associative recognition. Similar results may be produced by similar mechanisms. To instantiate recall processes in SAM, one might assume that subjects use test words to search for other words that accompanied them at study. It is likely that such a search would operate in addition to a familiarity-based mechanism, and that recognition performance would be based on the outcomes of these two processes.

Both of these modifications produce families of models that are somewhat complicated and very powerful, and the present results do not allow for a test between them. Thus, it seems premature to pursue the details of these modifications. Instead, Experiment 3 was an exploration of the generality of the high-frequency-word advantage in recognition.

Whatever mechanism produces the high-frequency-word advantage for associative recognition, it seems strange to assume that it plays no role whatsoever in old-new item recognition. For example, if one favors a recall-based explanation of the results of Experiments 1 and 2, is one to assume that recall operates only for associative recognition and never for item recognition? Similarly, do higher order associations never play a role in item recognition? If one assumes that the higher order unit is accessed by the intact triple, one should expect a high-frequency-word advantage for triple-item recognition in Experiment 2 (which was not shown). Experiment 3 was an examination of aspects of item recognition that show a highfrequency-word advantage; its purpose was to establish a continuity between associative and item recognition with regard to word frequency.

\section{EXPERIMENT 3}

The low-frequency-word advantage for triple-item recognition in Experiment 2 suggests that the factor operating in associative recognition (to produce a high-frequencyword advantage) does not operate in item recognition, even if all of the words from a study triple are present at test. On the other hand, associative factors may operate in item recognition, but not in such a way as to produce an overall high-frequency-word advantage. In tripleitem recognition, since all items are old $(A B C)$ or all are new $(X Y Z)$, a decision can be made if any single item is clearly old or clearly new. In this sense, the task is equivalent to single-item recognition, and one might expect a similar pattern of results.

The question is, then, under what conditions will associative factors operate to produce a high-frequencyword advantage for item recognition? Humphreys (1976, 1978) has argued that an item $B$ in an intact pair (or tri- 
ple) may be recognized if item-specific information is retrieved for that item, or, failing that, if item-specific information is retrieved for the other item in the pair $A$, and associative information linking $B$ to $A$ is retrieved.

For example, suppose HORSE-CLOCK is studied and tested as an intact pair. The task is to say "old" or "new" for each word. The subject may not be able to retrieve item information for CLOCK, but if item information is retrieved for HORSE, the associative information that links HORSE to CLOCK may be retrieved. Thus, CLOCK may be recognized via its association with HORSE, even if CLOCK itself is not recognized directly. This alternative retrieval route is not available for words tested outside of their original study context.

A critical aspect of Humphreys's $(1976,1978)$ proposal is that if item information is not retrieved for HORSE, the alternative route to CLOCK will not become available. Thus, the alternative retrieval route is not available unless at least one word in the intact pair (or triple) is recognized.

An important implication of this account is that the intact advantage is not produced at the level of individual words, but rather is due to associations between words. Thus, this account of the intact advantage is fundamentally different from the encoding match account. Moreover, the assumption that retrieval of associative information is contingent upon retrieval of item information accounts for why item recognition tasks in Experiment 2 (which can be made on the basis of a single word) did not show a high-frequency-word advantage, even when intact triples were tested. The low-frequency-word advantage in triple-item recognition may have occurred because the preconditions for retrieval of associative information (which presumably would have produced a high-frequency advantage) were sufficient for recognition decisions. Demonstration of a high-frequency advantage in item recognition may require a more complex design and more finegrained analyses.

In Experiment 3, high- and low-frequency-word pairs were presented. After each list, subjects were presented with intact $(A B)$, rearranged $(A D)$, mixed $(A X$ or $X B)$, old $(A$ or $B)$, new $(X)$, or new-new $(X Y)$ test pairs. The task was to respond "old" or "new" for each word.

The predictions are as follows. On the basis of previous results, an overall low-frequency-word advantage and an intact advantage should occur. However, the probability of recognizing at least one item would not differ for intact and rearranged pairs, because the associative information on which the intact advantage is based does not become available unless at least one item is recognized. The intact advantage would be produced because, given that one item is recognized, the probability of recognizing the other item is greater for intact pairs. Thus, the probability of recognizing both items (double hits) is higher for intact pairs. Experiment 3 also examined the extent to which doublehit rates for intact pairs exceed predictions based on independent decisions. Humphreys (1976) showed that double-hit rates for rearranged pairs were equal to the square of the unconditional hit rate for single items, but that double-hit rates for intact pairs exceeded this independence point. The critical prediction regarding word frequency was that for all of these measures, the intact advantage would be larger for high-frequency words than for low-frequency words, even though overall performance is better for low-frequency words.

\section{Method}

Subjects. Forty-eight different subjects from the pool used in Experiments 1 and 2 participated.

Materials and Procedure. High- and low-frequency words were chosen randomly from the word pool used in Experiments 1 and 2. Four lists of 20 word pairs were presented at a rate of $3 \mathrm{sec} / \mathrm{pair}$. Two lists consisted of high-frequency and two of low-frequency words. The subjects were instructed to learn the pairs by connecting the two words in each pair in a sentence or in a visual image. They were given complete information regarding the nature of the test conditions prior to presentation of the first list. After presentation of each list, the subjects performed a 30-sec mental arithmetic task, prior to starting the test.

On each of 24 test trials, the subjects were presented with one or two test words, and they were to give old-new judgments for each test word. Six kinds of test trial were presented: intact $(A B)$, rearranged $(A D)$, mixed $(A X)$, new-new $(X Y)$, old $(A)$, and new $(X)$. For mixed $(A X)$ and old $(A)$ test trials, the target word was the left member of a studied pair half of the time. New items $(X)$ appeared on the left or right equally often. Four repetitions of each test type were given.

Selection of words and assignment to conditions were both random for each subject. The order of study-test conditions was also randomly determined, as was the order of presentation within study and test sequences. Stimulus presentation and recognition response collection were controlled by Atari 1040ST computers.

\section{Results}

Unconditional probabilities of responding "old" are given in Table 3 for each test type for high- and lowfrequency words. Performance was measured by subtracting false alarm rates from hit rates. For words tested alone $(A$ or $X), p($ old $\mid A)-p($ old $\mid X)$ was calculated for each subject. For low-frequency words, this average difference was $.794-.107=.687$, and for high-frequency words, the difference was $.716-.177=.539$, thus showing a low-frequency-word advantage $[t(47)=3.23, p<.001]$.

The same HR-FAR measure calculated for pairs, $p($ old $\mid A B)-p($ old $\mid X Y)$, also showed an advantage for low-frequency words $(.690)$ over high-frequency words (.613) $[t(47)=2.17, p<.05]$. These results are consis-

Table 3

Probability of "Old" Response for Each Test Type for Highand Low-Frequency Words in Experiment 3

\begin{tabular}{lcc}
\hline \multirow{2}{*}{ Test Type } & \multicolumn{2}{c}{ Word Frequency } \\
\cline { 2 - 3 } Intact $(A B)$ & Low & High \\
Rearranged $(A D)$ & .832 & .811 \\
Mixed $(A \mid A X)$ & .766 & .699 \\
Mixed $(X \mid A X)$ & .768 & .714 \\
New-new $(X Y)$ & .143 & .214 \\
Old $(A)$ & .142 & .198 \\
New $(X)$ & .794 & .716 \\
\hline
\end{tabular}


Table 4

Probabilities for Double Hits, at Least One Hit, and Conditional Hits for Intact and Rearranged Pairs

\begin{tabular}{|c|c|c|c|}
\hline \multirow[b]{2}{*}{ Test Type } & \multicolumn{2}{|c|}{ Hits } & \multirow[b]{2}{*}{ Conditional } \\
\hline & Double & $\begin{array}{c}\text { At Least } \\
\text { One }\end{array}$ & \\
\hline \multicolumn{4}{|c|}{ Low-Frequency Words } \\
\hline Intact & .732 & .932 & .922 \\
\hline Rearranged & .596 & .935 & .751 \\
\hline Intact - Rearranged & .136 & -.003 & .171 \\
\hline \multicolumn{4}{|c|}{ High-Frequency Words } \\
\hline Intact & .711 & .911 & .993 \\
\hline Rearranged & .474 & .924 & .662 \\
\hline Intact - Rearranged & .237 & -.013 & .331 \\
\hline
\end{tabular}

Note-For independence comparisons, $p(\mathrm{~A})^{2}=.631$ for low-frequency words and .513 for high-frequency words.

tent with the results of previous experiments which show a LF word advantage, and with the results of Experiment 2 , which showed the low-frequency advantage to persist for words presented in intact groups.

On the basis of the contingency assumptions in Humphreys's (1976) model, it was predicted that the intact advantage would be larger for high-frequency words than for low-frequency words, but only for measures that are sensitive to associative information. This was investigated with the use of several dependent measures: (1) unconditional probabilities, (2) the probability of recognizing at least one word in a test pair, (3) double-hit probabilities, (4) conditional probabilities, and (5) deviation from independence baseline. The relevant data are shown in Table 4.

Of the first two measures, the unconditional hit probability is somewhat insensitive to associative information, and in Humphreys's (1976) model, the probability of recognizing at least one word is completely insensitive to retrieval of associative information. The other measures, however, should show large intact advantages that are larger for high-frequency words than for low-frequency words.

1. Unconditional probabilities. The intact advantage was computed as $p($ old $\mid A B)-p($ old $\mid A D)$, which was .066 for low-frequency words and .112 for high-frequency words. The intact advantage was thus larger for highfrequency words than for low-frequency words, but the difference was not statistically reliable $[t(47)=1.50]$. That this difference is small is not surprising, however, because the unconditional analyses are not as sensitive to the contingency of associative information upon item information as are the double-hit and conditional analyses.

2. Probability of recognizing at least one word. These data are shown in the middle column of Table 4, which gives the probability that $A$ or $B$ (or both) will be recognized. Obviously, there was no intact advantage and no differences between high- and low-frequency words.

3. Double-hit probabilities. The probability of recognizing both items was calculated separately for intact and rearranged pairs. Results are shown in the first column of Table 4. The difference, $p$ (both old $\mid A B)-p($ both old $\mid A D)$ provides a measure of the intact advantage, which was shown to be larger for high-frequency words (.237) than for low-frequency words $(.136)[t(47)=2.11, p<.05]$.

4. Conditional probabilities. The conditional probability of interest is the probability of an "old" response on the second decision, given that an "old" response was given on the first decision. This probability is denoted $p(B \mid A)$ and is defined as the double-hit probability divided by the unconditional hit rate or $p(A$ and $B) / p(A)$. The $A$ and $B$ terms do not refer to particular items in the pair, but rather to first (A) and second (B) decisions: $p(A$ and $B)$ is simply the double-hit rates that are given in Table 4 , and $p(A)$ is estimated from the hit rate for single-item tests that are in Table 3. The conditional probabilities are given in the right-hand column of Table 4.

The conditional probabilities for responding "old" for the second decision, given an "old" response for the first decision, are .993 and .922 for high- and low-frequency intact pairs, and .662 and .751 for high- and lowfrequency rearranged pairs. The intact advantage measured by subtracting conditional probabilities was .331 for high-frequency words and .171 for low-frequency words. A statistical analysis of these data was performed by obtaining a score for each subject, given as the doublehit probability divided by the subject's unconditional hit probability (estimated from single-item tests). For each subject, the intact advantage was given as the difference between these scores for intact and rearranged pairs. This analysis showed that the intact advantage was larger for high-frequency words than for low-frequency words $[t(47)$ $=2.35, p<.03]$.

5. Deviation from independence. For paired tests, double-hit probabilities will be equal to the square of the unconditional hit probability if the two decisions are made independently. Table 4 shows the relations between doublehit rates and predictions based on independence. For rearranged pairs, the double-hit probabilities for both high(.474) and low-frequency (.596) words were very close to the independence prediction (high frequency $=.51$; low frequency $=.63 ; p>.10$ for both comparisons).

However, double-old probabilities for intact pairs exceeded independence predictions for both high- (.711) and low-frequency $(.73)$ words $[t(47)=6.86, p<.001$ for high-frequency words and $t(47)=3.17, p<.01$ for lowfrequency words]. Moreover, the deviation from independence was larger for high-frequency words than for lowfrequency words $[t(47)=2.59, p<.02]$.

\section{Discussion}

Recognition of single words, tested alone and in pairs, was better for low- than for high-frequency words, thus replicating the standard WFE for item recognition. Also, item recognition was better for words in intact than in rearranged pairs, thus demonstrating an intact advantage (Humphreys, 1976, 1978).

However, although low-frequency words were recognized better than high-frequency words, the size of the intact advantage was larger for high-frequency words overall. This was shown with several dependent measures: 
double-hit rates, conditional hit rates, and deviation from independence. Thus, what makes recognition good does not make intact better. This dissociation between overall performance and the size of the intact advantage suggests the operation of two separate components for old-new item recognition. Moreover, the results are consistent with the proposal that access to associative information is contingent upon retrieval of item-specific information.

The results were inconsistent with an encoding match explanation of context effects in item recognition. No intact advantage was shown for the probability of recognizing at least one item in a test pair, but large advantages were shown with the use of recognition measures that were sensitive to the conditional probabilities. The lack of an intact advantage for recognizing at least one word may have been due in part to a ceiling effect, since performance in all cases was above .90 . Given this caveat, the encoding match account cannot be rejected unequivocally. However, this does not take away from the major result: a low-frequency-word advantage overall, but a high-frequency advantage when intact and rearranged test pairs are compared. This dissociation occurred within an item recognition task, and it parallels the result found when item and associative recognition were compared in Experiments 1 and 2.

Also, the results of Experiment 3 provide insight into triple-item recognition in Experiment 2. For both experiments, a low-frequency-word advantage was shown. In Experiment 2, subjects called the test triple "old" if any word was judged to be from the list. According to the contingency assumption in Humphreys's $(1976,1978)$ model, the associative information (which would produce a highfrequency-word advantage) would only come into play if item information were retrieved for at least one word. Thus, the precondition for retrieving associative information may have been sufficient for subjects to make the recognition decision.

\section{GENERAL DISCUSSION}

Experiments 1 and 2 showed that associative recognition performance is better for high- than for low-frequency words. This result constitutes a reversal of the standard WFE for recognition. The high-frequency advantage in associative recognition occurred concurrently with a lowfrequency advantage in item recognition. Experiment 3 showed that, for item recognition, the advantage for intact pairs, assumed to be due to associative factors, was larger for high-frequency words, even though overall, item recognition was better for low-frequency words. The results of Experiment 3 provide evidence for two components in recognition and suggest a dependent relationship between item-specific and associative information.

Results from Experiments 2 and 3 were inconsistent with a single-component model augmented with assumptions regarding encoding match. Triple-item recognition did not show a high-frequency advantage in Experiment 2, and the probability of recognizing at least one item in a test pair was the same for intact and rearranged pairs in Experiment 3.

The overall pattern of results has important implications for explanations of the WFE, and for models of recall and recognition in general. In particular, the demonstration of high-frequency advantages in associative and item recognition complicates a picture that is typically taken to show clear evidence for a process distinction between recall and recognition. Given the present results, one can no longer simply say that high-frequency words are recalled better and that low-frequency words are recognized better.

\section{Explanations of Word Frequency Interactions in Recognition Memory}

Three factors were identified as potentially contributing to the differential effects of word frequency in recognition memory: encoding match, recall, and higher order units. Although it is probably premature to completely rule out any contribution of encoding match, the data from Experiments 2 and 3 suggest that its role is limited. Therefore, I will focus on the higher order unit and recall explanations.

Higher order units. In SAM (and other associative network models), words are stored in separate units, and associations are represented as connections between units. The reason why this item-level version of SAM cannot predict the word frequency interactions is the following. Familiarity of a single test word is given as the sum of the strengths of its connections to all of the words on the list, including, in the case of word pairs, its association to $B$. Thus, the familiarity of $A$ increases as the $A-B$ association strength increases. It is also the $A-B$ association that allows the intact test pair $A B$ to be distinguished from the rearranged pair $A D$. Thus, to predict a highfrequency advantage for associative recognition, it must be assumed that the $A-B$ associations are stronger for highfrequency words than for low-frequency words. However, because the $A-B$ association also contributes to the familiarity of $A$ tested alone, this assumption produces a highfrequency advantage for item recognition as well, contrary to data.

One way to modify SAM is to assume that the $A-B$ associative strength, or at least some component of it, contributes only to the familiarity of the $A B$ test pair, but not to the familiarity of $A$ alone. One way of doing this is to represent the $A-B$ association as a single higher order associative unit (denoted $A B$ ). Such proposals have been made previously within the SAM model framework by Shiffrin et al. (1988). By separating the association $(A B)$ from its components ( $A$ and $B$ ), one can make additional assumptions that will allow the model to predict different effects of word frequency for item and associative recognition. Specifically, it may be assumed that the contribution of the $A B$ unit to the familiarity of the $A B$ test pair is greater for high-frequency words than for low-frequency 
words, but that the contribution of the $A B$ unit to the familiarity of $A$ (or $B$ ) alone is not greater for high- than for low-frequency words.

Recall-based retrieval. Another explanation for the word frequency interaction is to assume that recall-like retrieval processes operate in recognition. Such proposals have been made previously (Humphreys, 1978; Mandler, 1980; Wolford, 1971) for multiple-word recognition. Specifically, for word pair $A B$, subjects may recognize $B$ by using $A$ as a cue to recall $B$, even if $B$ itself is unfamiliar (but the link from $A$ to $B$ is strong). In associative recognition, $A D$ may be rejected by the same processes, using $A$ to recall $B$, and thus to rule out $A D$. Incorporating a recall component into current recognition models would be very complicated, although in principle, any of the current models could be modified to make specific assumptions regarding how recall might operate in conjunction with global matching.

\section{Relations Between Recall and Recognition}

The present results show that, relative to low-frequency words, high-frequency words were recalled better and were recognized better in associative discriminations, and that they produced a larger intact advantage in item recognition. The obvious question is whether these similar results are produced by similar or different mechanisms.

Using a slightly different procedure, Clark and Shiffrin (in press) showed that while associative recognition performance increased with study time, the amount of facilitation due to reinstating verbal context for item recognition tests did not increase with study time. On the basis of these results, it was argued that associative recognition and context-dependent facilitation in item recognition are based, at least in part, on different mechanisms. It is likely that all of the factors discussed in this paper-higher order associations, recall, and encoding match-play various roles in item and associative recognition.

Regarding the relationship between recall and recognition, the present results indicate that the boundary between recall and recognition is not as well defined as previous word frequency results have suggested. It is likely that recognition is much more complex than is currently assumed by global matching models, sharing components with recall. The present results suggest that this is the case for associative recognition and, to a lesser extent, for item recognition. Just what these components are, and how they operate together, is an important question for future research.

\section{REFERENCES}

ANDERSON, J. R. (1974). Retrieval of propositional information from long-term memory. Cognitive Psychology, 6, 451-474.

Anderson, J. R., \& Bower, G. H. (1972). Recognition and retrieval processes in free recall. Psychological Review, 79, 97-123.

Atkinson, R. C., JuolA, J. F. (1974). Search and decision processes in recognition memory. In D. H. Krantz, R. C. Atkinson, R. D. Luce, \& P. Suppes (Eds.), Contemporary developments in mathematical psychology: Vol. I. Learning, memory, \& thinking (pp. 242-293). San Francisco: W. H. Freeman.
Balota, D. A., Neely, J. H. (1980). Test-expectancy and wordfrequency effects in recall and recognition. Joumal of Experimental Psychology: Human Learning \& Memory, 6, 576-587.

BAIN, J. D., HUMPhREys, M. S. (1988). Relational context: Independent cues, meanings, or configurations? In G. M. Davies \& D. M. Thomson (Eds.), Memory in contex: Contex in memory (pp. 97-137). New York: Wiley.

Clark, S. E., Shiffrin, R. M. (1987). Recognition of multiple-item probes. Memory \& Cognition, 15, 367-378.

Clark, S. E., \& Shifrrin, R. M. (in press). Cuing effects and associative information in recognition memory. Memory \& Cognition.

EYSENCK, M. W. (1979). Depth, elaboration, and distinctiveness. In L. S. Cermak \& F. I. M. Craik (Eds.), Levels of processing in human memory (pp. 89-118). Hillsdale, NJ: Erlbaum.

Gillund, G., Shifrein, R. M. (1984). A retrieval model for both recognition and recall. Psychological Review, 91, 1-67.

Glanzer, M., a Adams, J. K. (1985). The mirror effect in recognition memory. Memory \& Cognition, 13, 8-20.

Glanzer, M., \& Adams, J. K. (1990). The mirror effect in recognition memory: Data and theory. Jourmal of Experimental Psychology: Learning, Memory, \& Cognition, 16, 5-16.

Greene, R. L. (1990). Memory for pair frequency. Journal of Experimental Psychology: Leaming, Memory, \& Cognition, 16, 110-116.

GREGG, V. (1976). Word frequency, recognition, and recall. In J. Brown (Ed.), Recall and recognition (pp. 183-216). London: Wiley.

HintzMAN, D. L. (1984). MINERVA 2: A simulation model of human memory. Behavioral Research Methods, Instruments, \& Computers, 16, 96-101.

HINTZMAN, D. L. (1988). Judgments of frequency and recognition memory in a multiple-trace memory model. Psychological Review, 95, 528-551

HUMPHREYS, M. S. (1976). Relational information and the context effect in recognition memory. Memory \& Cognition, 4, 221-232.

HUMPHREYS, M. S. (1978). Item and relational information: A case for context independent retrieval. Joumal of Verbal Leaming \& Verbal Behavior, 17, 175-187.

Hunt, R. R., Einstein, G. O. (1981). Relational and item-specific information in memory. Joumal of Verbal Learning \& Verbal Behavior, 20, 497-514.

JASTRZEMBSKI, J. E. (1981). Multiple meanings, number of related meanings, frequency of occurrence, and the lexicon. Cognitive Psychology, 13, 278-305

KINTSCH, W. (1970). Models for free recall and recognition. In D. A Norman (Ed.), Models of human memory (pp. 333-374). New York: Academic Press.

KINTSCH, W. (1978). More on recognition failure of recallable words: Implications for generation-recognition models. Psychological Review, $85,470-473$.

KUCERA, H., \& FrANCIS, W. N. (1967). A computational analysis of present-day American English. Providence, RI: Brown University Press.

LEWANDOWSKy, S., MURDock, B. B., JR. (1989). Memory for serial order. Psychological Review, 96, 25-57.

Light, L. L., CARTER-Sobell, L. (1970). Effects of changed semantic context on recognition memory. Journal of Verbal Learning \& Verbal Behavior, 9, 1-11.

Lockhart, R. S., Craik, F. I. M., \&acoby, L. (1976). Depth of processing, recognition, and recall. In J. Brown (Ed.), Recall and recognition (pp. 75-102). New York: Wiley.

MANDLER, G. (1980). Recognizing: The judgment of previous occurrence. Psychological Review, 87, 252-271.

MurDock, B. B. , JR. (1974). Human memory: Theory and data. Hillsdale, NJ: Erlbaum.

MURDock, B. B., JR. (1982). A theory for the storage and retrieval of item and associative information. Psychological Review, 89, 609-626.

Murdock, B. B., JR., OGILVIE, J. C. (1968). Binomial variability in short-term memory. Psychological Bulletin, 70, 256-260.

MUTER, P. (1984). Recognition and recall of words with a single meaning. Joumal of Experimental Psychology: Leaming, Memory, \& Cognition, 10, 198-202. 
Mutter, S. A., Hashtroudi, S. (1987). Cognitive effort and the word frequency effect in recognition and lexical decision. American Journal of Psychology, 100, 93-116.

PIKE, R. (1984). A comparison of convolution and matrix distributed memory systems. Psychological Review, 91, 281-294.

RaAiumakers, J. G. W., \& Shiffrin, R. M. (1980). SAM: A theory of probabilistic search of associative memory. In G. H. Bower (Ed.), The psychology of learning and motivation (Vol. 14, pp. 207-262). New York: Academic Press.

RAO, K. V., ProctoR, R. W. (1984). Study-phase processing and the word frequency effect in recognition memory. Journal of Experimental Psychology: Leaming, Memory, \& Cognition, 10, 386-394.

REDER, L. M., ANDerson, J. R., B BJork, R. A. (1974). A semantic interpretation of encoding specificity. Joumal of Experimental Psychology, 102, 648-656.

Schulman, A. I. (1974). The declining course of recognition memory. Memory \& Cognition, 2, 14-18.

Schulman, A. I. (1976). Memory for rare words previously rated for familiarity. Journal of Experimental Psychology: Human Leaming \& Memory, 2, 301-307.

Shiffrin, R. M., Murnane, K., Gronlund, S., \& Roth, M. (1988). On units of storage and retrieval. In C. Izawa (Ed.), Current issues in cognitive processes: The Tulane Floweree Symposium on Cognition (pp. 25-68). Hillsdale, NJ: Erlbaum.

ThORNDIKE, E. L., LORGE, 1. (1944). The teacher's word book of 30,000 words. New York: Columbia University Press.

WOLFORD, G. (1971). Function of distinct associations for pairedassociate performance. Psychological Review, 78, 303-313.

\section{NOTES}

1. Absent from this discussion is the fact that recognition performance for very low-frequency words (less than one occurrence per million) is often lower than that for words typically defined as low frequency (less than four per million) (Rao \& Proctor, 1984; Schulman, 1976). These very low-frequency words may be functional nonwords for subjects. This finding is not critical to the present endeavor, however, since word frequency predictions of the SAM recognition model are parameterspecific. Presumably, SAM could account for this result if the parameters were adjusted. A more critical test for the model is the comparison between item and associative recognition.

2. The number of study list items and the number of test trials are limited by the rearranged test pairs, which require two study list pairs ( $A D$ created from $A B$ and $C D$ ). Throughout the paper, when the number of test trials for a given condition is such that not all study list pairs (or triples) are tested, those that are not tested are randomly determined. These constraints and conditions apply to Experiments 2 and 3 as well

3. When neither HR nor FAR takes on extreme values (close to 1 or 0 ), there is usually a close correspondence between HR - FAR and $d^{\prime}$. In $d^{\prime}$ analyses, it is necessary to estimate HR and FAR whenever they equal 1 or 0 . Several procedures have been proposed for doing this. HR and FAR were estimated in two different ways in separate analyses; one was based on Murdock and Ogilvie's (1968) procedure, in which the estimates are sensitive to the number of test trials. However, because item and associative recognition conditions had different numbers of test trials, an additional analysis was conducted in which zero values were set to .02 and values of 1 were set to .98 . The differences between these analyses were minimal.

4. The assumptions described for the higher order unit SAM model are similar to those of Murdock's (1982) TODAM. Presumably, the models would predict similar patterns of results. Application of TODAM to word frequency data is limited (but see Lewandowsky \& Murdock, 1989), but the present analysis suggests that further applications of TODAM to the WFE could be promising.

\section{APPENDIX}

The purpose of this Appendix is to give quantitative details regarding recall and recognition. For recall, the sampling and recovery rules are given. For recognition, a general equation for familiarity is given, and expressions for expectations, vari- ances, and $d^{\prime}$ are given for single-item and associative recognition. Additional details of the models may be found in Clark and Shiffrin (in press), Gillund and Shiffrin (1984), and Raaijmakers and Shiffrin (1980).

\section{Sampling and Recovery in Recall}

Recall of an image is a two-step process in which cues are used to sample a given image and then recover sufficient information from the image to allow the word to be output.

The probability of sampling image $I_{j}$, given cues $Q_{1}, Q_{2}, Q_{3}$, $\ldots, Q_{\mathrm{M}}$ is

$$
P_{S}\left(I_{j} \mid Q_{1}, Q_{2}, Q_{3}, \ldots, Q_{M}\right)=\frac{\prod_{i=1}^{M} S\left(Q_{i}, I_{j}\right)^{w_{i}}}{\sum_{j=1}^{N} \prod_{i=1}^{M} S\left(Q_{i}, I_{j}\right)^{\omega_{i}}},
$$

where $S\left(Q_{i}, I_{j}\right)$ is the retrieval strength between cue $Q_{i}$ and image $I_{j}, M$ is the number of cues, $N$ is the number of items in memory (functionally the list length), and $w_{i}$ is a weight on $Q_{i}$. It can be seen from Equation $A 1$ that sampling is based on the strength of the cue set to image $l_{j}$, relative to the strength of the cues to other images in memory.

Once sampled, a given image must be recovered in order to be recalled. The recovery rule is given below:

$$
P_{R}\left(I_{j} \mid Q_{1}, Q_{2}, Q_{3}, \ldots, Q_{M}\right)=1-\exp \left[\sum_{i=1}^{M} w_{i} S\left(Q_{i}, I_{j}\right)\right]
$$

Recovery is based on an exponential function, and unlike sampling, it is based on the absolute strength of the cues to the image to be recovered.

\section{Recognition Model and Derivations}

Recognition is based on the familiarity of the test item(s) that are used as cues, along with a context cue, to probe memory. The familiarity for cues $Q_{1}, Q_{2}, Q_{3}, \ldots, Q_{M}$ (where context is one of the cues) is:

$$
F\left(Q_{1}, Q_{2}, Q_{3}, \ldots, Q_{M}\right)=\sum_{j=1}^{N} \prod_{i=1}^{M} S\left(Q_{i}, I_{j}\right)^{w_{j}}
$$

It can be seen that Equation $\mathrm{A} 3$ is the denominator of the sampling rule in Equation Al. Familiarity, then, is the summed strength of the cues to all images in memory

Equation $\mathrm{A} 3$ gives an approximation to the expectation for familiarity for a given cue set. However, it is assumed that each $S\left(Q_{i} I_{j}\right)$ is a random variable that produces distributions of familiarity for each test type $T$, with expectation $E[T]$ and variance VAR[T]. Response probabilities for a given test type can be obtained with Monte Carlo simulation, or through derivation of the expectations and variances. Closed form expressions for the expectations, variances, and $d^{\prime}$ for item and associative recognition are given below.

Predictions from the SAM model can be obtained for any test condition by deriving expressions for the expectation and standard deviation of the familiarity distributions for relevant test conditions.

Given below are the expectations and variances for targets and distractors for item ( $A$ vs. $X$ ) and associative ( $A B$ vs. $A D$ ) recognition. In the equations, the following parameters are used: $a, b, c$, and $d$ are context, interitem, self-, and residual retrieval strengths. Cue weights are as follows: $w_{c}$ for context; $w_{s}$ for the test item in single-item recognition; $w_{p}$ for each item in a pair test. (Normally, $w_{\mathrm{c}}=w_{\mathrm{s}}=.5, w_{\mathrm{p}}=.25$, and all weights 
sum to 1.0.). The $\theta(w)$ terms are adjustment factors, reflecting the fact that $E\left[X^{2}\right] \neq E[X]^{2}$. It is assumed that for any strength with mean $M$, the probability that the true strength equals $\gamma_{i} M$ is $p_{i}$. That is, $P\left[S=\gamma_{i} M\right]=p_{i} . \theta(w)$ is then defined: $\theta(w)=$ $\Sigma \gamma_{i}^{w} p_{i}$, for any $w$.

The values of the $\theta$ terms depend on the particular variance assumptions made. Gillund and Shiffrin (1984) assumed the following. For any cue-to-image strength $S\left(Q_{i}, I_{j}\right)$ given by parameter value $x$, the true value of $x$ takes on values of $x(1+v), x$, or $x(1-v)$, each with a probability of $1 / 3$. Given these variance assumptions, the $\theta$ terms are calculated as follows: $\theta(w)=$ $\left[(1+v)^{w}+1+(1-v)^{w}\right] / 3$, where $v=.5$.

For single-item recognition, target and distractor expectations are:

$$
\begin{aligned}
& E[A]=\theta\left(w_{\mathrm{c}}\right) \theta\left(w_{\mathrm{s}}\right) a^{w_{\mathrm{c}}}\left[b^{w_{\mathrm{s}}}+c^{w_{\mathrm{s}}}+(N-2) d^{w_{\mathrm{s}}}\right], \\
& E[X]=\theta\left(w_{\mathrm{c}}\right) \theta\left(w_{\mathrm{s}}\right) N a^{w_{\mathrm{c}}} d^{w_{\mathrm{w}}},
\end{aligned}
$$

and target and distractor variances are

$$
\begin{aligned}
\operatorname{VAR}[A]= & a^{2 w_{\mathrm{c}}}\left[\theta\left(2 w_{\mathrm{c}}\right) \theta\left(2 w_{\mathrm{s}}\right)-\theta^{2}\left(w_{\mathrm{c}}\right) \theta^{2}\left(w_{\mathrm{s}}\right)\right] \\
& \cdot\left[(N-2) d^{2 w_{\mathrm{s}}}+b^{2 w_{\mathrm{s}}}+c^{2 w_{\mathrm{s}}}\right], \\
\operatorname{VAR}[X]= & {\left[\theta\left(2 w_{\mathrm{c}}\right) \theta\left(2 w_{\mathrm{s}}\right)-\theta^{2}\left(w_{\mathrm{c}}\right) \theta^{2}\left(w_{\mathrm{s}}\right)\right] N a^{2 w_{\mathrm{c}}} d^{2 w_{\mathrm{s}}} . }
\end{aligned}
$$

For associative recognition, expectations for intact $(A B)$ and rearranged $(A D)$ pairs are

$$
\begin{aligned}
E[A B]= & \theta\left(w_{\mathrm{c}}\right) \theta^{2}\left(w_{\mathrm{p}}\right) a^{w_{\mathrm{c}}}\left[2 b^{w_{\mathrm{p}}} c^{w_{\mathrm{p}}}+(N-2) d^{2 w_{\mathrm{p}}}\right], \\
E[A D]= & \theta\left(w_{\mathrm{a}}\right) \theta^{2}\left(w_{\mathrm{p}}\right) a^{w_{\mathrm{c}}} \\
& \cdot\left[b^{w_{\mathrm{p}}} d^{w_{\mathrm{p}}}+c^{w_{\mathrm{p}}} d^{w_{\mathrm{p}}}+(N-4) d^{2 w_{\mathrm{p}}}\right] .
\end{aligned}
$$

Corresponding variances are

$\operatorname{VAR}[A B]=\psi_{\mathrm{p}} a^{2 w_{\mathrm{c}}}\left[2 c^{2 w_{\mathrm{p}}} b^{2 w_{\mathrm{p}}}+(N-2) d^{4 w_{p}}\right]$,

$$
\operatorname{VAR}[A D]=\psi_{p} a^{2 \omega_{q}}\left[\left(2 c^{2 \omega_{p}} d^{2 w_{p}}+b^{2 w_{p}} d^{2 w_{p}}+(N-4) d^{4 w_{p}}\right],\right.
$$

where $\psi_{p}=\theta\left(2 w_{c}\right) \theta^{2}\left(2 w_{p}\right)-\theta^{2}\left(w_{c}\right) \theta^{4}\left(w_{p}\right)$.

From these terms, predictions can be obtained for item and associative recognition. Hit and false alarm rates can be obtained by assuming normal distributions; the hit rate is the proportion of the target distribution above a decision criterion, and the false alarm rate is the proportion of the distractor distribution above that same criterion. A much simpler method is to give predictions in terms of $d^{\prime}$, given as the difference between the means of target and distractor distributions relative to the standard deviation of the distractor distribution. For single-item recognition, $d^{\prime}$ is given by: $E[A]-E[X] / \operatorname{VAR}[X]^{1 / 2}$. Recognition $d^{\prime}$ is given as

$$
d_{s}^{\prime}=\left(\alpha / N^{1 / 2}\right)\left[(c / d)^{\omega_{1}}+(b / d)^{\omega_{1}}-2\right] .
$$

For associative recognition, $d^{\prime}=E[A B]-E[A D] / \operatorname{VAR}[A D]^{\text {th }}$ :

$$
d_{\mathrm{a}}^{\prime}=\left(\alpha / N^{1 / 2}\right) 2\left[(c / d)^{\omega_{\mathrm{p}}}+1-(c / d)^{\omega_{\mathrm{p}}}+(b / d)^{\omega_{\mathrm{p}}}\right] .
$$

(The $\alpha$ terms are obtained by dividing out the $\theta$ terms). The equations show that for both item and associative recognition, $d^{\prime}$ increases with $b$ and $c$, and decreases with increases in $d$. Since word frequency predictions are based on differences in $b$ and $d$, word frequency predictions will go in the same direction for item and for associative recognition.

(Manuscript received March 6, 1991; revision accepted for publication November 12, 1991.) 